\title{
Assessment of the Reading Intervention Program Beginning Reading Para sa mga Tsikiting (BRPT): A Focus on its Progress and Challenges
}

\author{
Ariel U. Cubillas, PhD \\ Caraga State University, Ampayon Campus, Butuan City, Philippines \\ aucubillas@carsu.edu.ph \\ DOI: 10.29322/IJSRP.11.11.2021.p11909 \\ http://dx.doi.org/10.29322/IJSRP.11.11.2021.p11909
}

\begin{abstract}
The primary intention of this paper is to assess the reading intervention program called Beginning Reading Para sa mga Tsikiting or BRPT. It also gauged the improvement of the reading performance of the beginning readers who participated in the BRPT and identify the challenges encountered by the reading intervention program implementers. This study utilized the descriptive design of research. It used the results of the Revised Phil- IRI Reading Profile as its baseline in determining the improvement of the reading skills of the learners in the primary grade. Complete enumeration was used in this study. There were 125 primary grade pupils who were included in the study. After getting the reading profile of the learners, the researcher then proceeded to the employment of the reading intervention program activities which include the training of teachers and home teachers or parents, crafting of beginning reading instructional materials in Mother Tongue, and the initial conduct of the online reading tutorial. The study identified 37 learners in frustration level and the 20 non-readers who need much intervention. The series of training, reading intervention related-activities, and the development and validation of beginning reading instructional materials were conducted to realize the BRPT objectives that is to increase the level of reading performance of the beginning readers. Further, evidence show that there were eleven (11) non-readers who need much intervention thus, they need an intensive reading intervention which can be done through online reading tutorial, one of the suggested activities in BRPT. Despite this result, it can still be said that the reading intervention program has improved the level of reading performance of the beginning readers and it was able to achieve its target objective.
\end{abstract}

\section{Index Terms}

challenges, progress, reading intervention program, and reading performance

\section{INTRODUCTION}

The quest for quality education has been a challenging journey especially by developing countries and this brings forth the inclusion of Goal 4 Quality Education of the UN Sustainable Development Goals (SDG). This goal ensures that all girls and boys complete free primary and secondary schooling by 2030. However, research findings do not entirely support this goal as a number of which highlight the increasing level of dropouts in schools in most developing countries. This drop-out rate is attributed to poor reading readiness. Therefore, children with inadequate reading skills usually participate in the pullout course (Donley, Baenen, Hundley, 1993 in NDCP, 2021). Researchers now believe that it is better to intervene early and give the needed services to stop these learners from developing a pattern of failure.

It is a requirement for each person to understand how to read with understanding. He should be capable of understanding simple texts. With the power to grasp a text, people are able not only to thrive safely and productively, but also to develop socially, emotionally, and intellectually (Umali, 2012 in Cubillas \& Ventura, 2021) and this is also emphasized in the attainment of improved Philippine educational services identified as one of the thrusts of AmBisyon Natin 2040 (NEDA, 2016) and such PH vision is additionally strengthened by the initiative of the DepEd's Sulong Edukalidad: Battlecry Moving Forward Amidst the Pandemic. It is easier to live with the matatag (stable), maginhawa (prosperous) at panatag (peaceful) kind of life if an individual has attained basic and functional literacy. As Murray in Munger (2016) noted, literacy requires simple comprehension; the latter always starts with word recognition and word recognition is attained during the start reading phase.

Blachmann as mentioned by Denton and Otaiba (2015) opined that at the foremost level, beginning readers must become tuned in to individual sounds and groupings of sounds within the oral speech stream. Oral communication consists of words composed of syllables that are successively composed of individual sounds; however, when an individual listens to oral speech, these words and word parts tend to run together. The beginning reader must become aware that oral language is formed of these components, a competency commonly considered as phonological awareness. This teaching of this phonemic awareness may be a challenge among teachers whose learners do not have much support from the parents since their first education is to start at their respective homes. This is often the first reason why the reading intervention program 
called Beginning Reading Para sa mga Tsikiting was conceptualized and implemented by the College of Education faculty with its extension partner school/target beneficiary, a public elementary school in West Butuan District 2, Butuan City Division.

Beginning Reading Para sa mga Tsikiting or BRPT believes that early intervention is vital for learners who are struggling with reading. This reading intervention program was implemented in October 2019. It complemented the regular classroom instruction in the early year of its implementation. A modification of the implementation scheme of BRPT took place as the threat of COVID-19 surfaced which includes modification on the training modality/set up that is from face-toface to virtual venue. Despite this alteration of the implementation mode, BRPT implementers still manage to continue delivering online workshops and other reading intervention- related activities.

To identify the challenges and also the improvements made on the reading skills of the beginning readers, the reading intervention program needs to be assessed. An assessment provides the BRPT implementers with information on the areas which require improvement. It is needed to help identify the level of success they had made in the implementation of the BRPT. The researchers then came up with this investigation.

\section{Objectives of the Study}

The primary intention of this investigation is to gauge the improvement of the reading

level of the beginning readers who undergo the BRPT reading intervention program. It specifically sought to attain the following objectives:

1.1 identify the demographic profile of the learners who undergo the reading intervention program in terms of sex and grade level;

1.2 determine the level of reading performance of the primary grade pupils before the implementation of the reading intervention program;

1.3 ascertain the intervention activities employed to increase the level of the beginning reading performance of the primary grade pupils;

1.4 point out the level of reading performance of the primary level pupils after the BRPT implementation;

1.5 compare the level of reading performance of the primary pupils before and after the BRPT implementation;

1.6 establish the difference between the level of reading performance of the primary pupils before and after the BRPT implementation; and

1.7 explore the challenges met by the implementers of the BRPT.

\section{METHODOLOGY}

\section{Research Design}

This study utilized the descriptive design of research. It used the results of the Revised Phil- IRI Reading Profile as its baseline in determining the improvement of the reading skills of the learners in the primary grade. It also served as one of the bases in gauging the success of the reading intervention.

\section{Sampling Design}

Complete enumeration was used in this study. All primary grade learners in the target public elementary school in West Butuan District II were included as participants. As to the implementation of the reading intervention, the BRPT implementers targeted the learners who belong to the frustration level (struggling readers) and the non-readers hence, nonprobability sampling technique particularly purposive sampling was utilized. The participants were chosen based on the PhilIRI Group Screening Test.

\section{Data Gathering Procedure}

As an offshoot of the extension project BRPT, the researchers were able to collect data from the School Reading Profile. From the document, the profile of the learners that include their grade level, sex, and reading level were extracted. The data in the document was gathered by the teachers. They were able to determine the grade level in which the pupil can register his or her reading profile in independent, instructional and frustration level. It is expected that the pupil has read two or more passages and answered the questions that follow. The number of passages the pupil has read was dependent on the result of each test. In finding the independent level of the pupil's reading profile, the teacher gave a selection that was one lower level than the given selection until the pupil registered performance at $97 \%-100 \%$ in the word recognition and $80 \%-100 \%$ in comprehension. In finding the frustration level, the teacher gave a selection that was one higher level than the level in which the child has registered instructional level until the pupil registered the performance at $89 \%$ and below for the word recognition and $58 \%$ and below for the comprehension.

After getting the reading profile of the 125 primary grade pupils, the researchers then proceeded to the employment of the reading intervention program activities which include the training of teachers and home teachers or parents, crafting of beginning reading instructional materials in Mother Tongue, and assessment of the intervention program itself. After the employment of the reading intervention program, BRPT, a similar procedure as that of the one used before the implementation of the BRPT was conducted to determine the new reading profile of the learners. When the researchers were able to gather the relevant data, frequency and percentages as well as Paired t-test were employed. The documentation of the challenges in the This publication is licensed under Creative Commons Attribution CC BY. 
implementation of the reading intervention program was taken from the interview of the teachers and home teachers or parents in the target public elementary school.

\section{RESULTS}

The Profile of the Primary Pupils of BRPT in terms of Sex and Grade Level

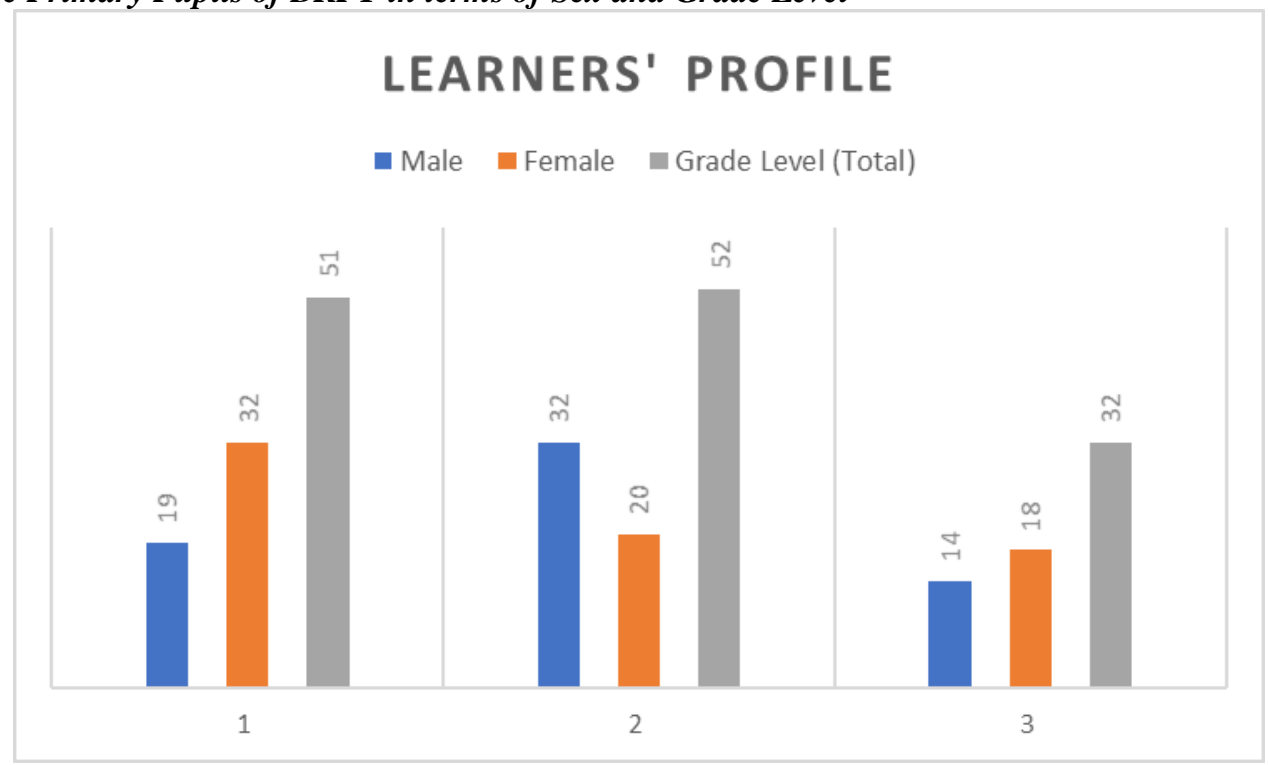

Fig. 1 Learners' Profile in terms of Sex and Grade Level

As shown in the figure, the highest number of learners are from the second graders or Grade 2 with 32 male and 20 female learners. The lowest number is in the third grade or Grade 3 with 32 learners; 14 are male and 18 are female learners. It can be noted that there is a significant decrease of the number of learners in the third grade.

Research revealed gender differences in reading competence between children and adolescents, whereas gender differences are small to non-existent in adulthood. Furthermore, a homogenous pattern of gender differences in reading for youngsters and adolescents, but not for adults, has become evident: generally, female students consistently tend to be more competent in reading than male students (Chiu and McBride-Chang 2006; Klieme et al. 2010; OECD 2019; Reiss et al. 2016; Thums et al., 2020).

Moreover, in line with Child Trends DataBank (2019) in their study conducted among the three grade levels, at all levels, girls have higher reading scores, on average, than boys. This reading scores have followed similar patterns over the past 15 years.

Level of Reading Skill of the Primary Level Pupils Before the BRPT Implementation

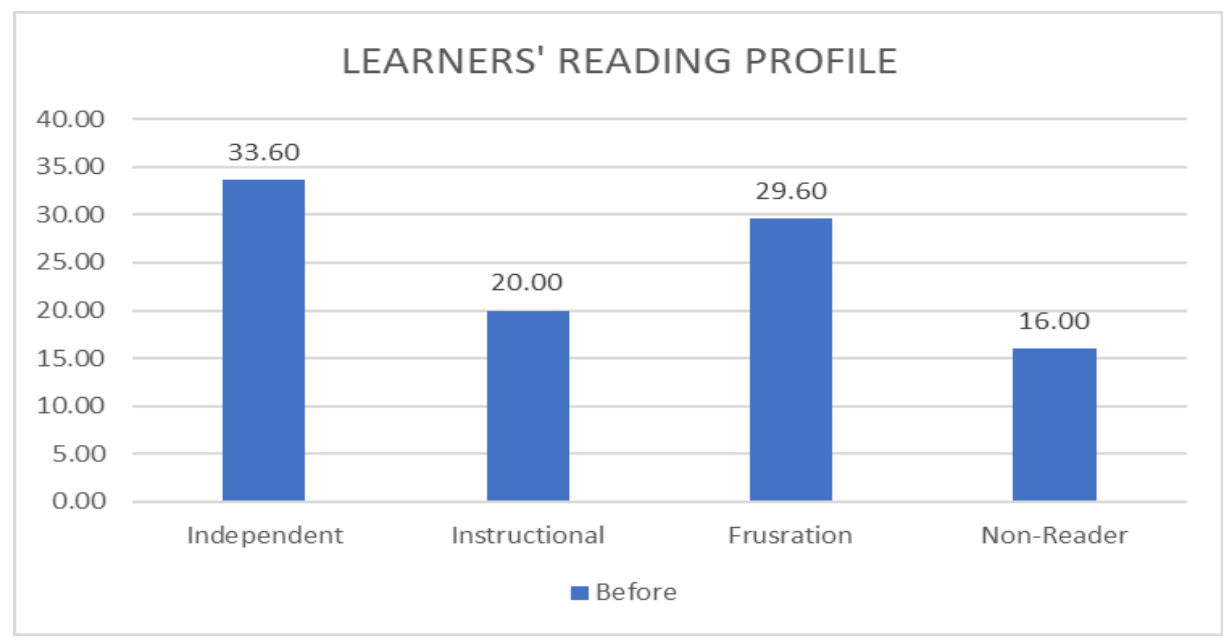


Fig. 2 The Learners' Reading Level Before the BRPT Implementation

Figure 2 presents the reading levels of the primary grade learners before the implementation of the BRPT. Out of 125 learners, $33.60 \%$ or 42 of them are in the independent level; $20 \%$ or 25 are in the instructional level; 29.60 or 37 are in the frustration level; $16 \%$ or 20 of them are non- readers. This means that majority of the learners can read independently with ease and without the assistance of an adult or teacher. The identified 37 learners in frustration level and the 20 non- readers need much intervention for these pupils cannot understand the meaning of the text, cannot decode words, and worst, they cannot blend sounds yet.

In consonance to the results above, struggling and non-readers or at-risk children according to NDPC (2021) are in critical need of effective instruction in the early years so as to develop effective reading and writing skills. Researchers believe that it is better to intervene early and provide the required services to stop students from developing a pattern of failure.

\section{Intervention Activities Employed by BRPT to Increase the Level of the Beginning Reading Performance of the Primary Grade Pupils}

The BRPT implementers conducted the following activities to achieve it primary goal that is to improve the level of reading performance of the primary grade learners.

\section{- Series of Training}

The BRPT were able to hold a series of training which includes the Beginning Reading Para sa Tsikiting (BRPT) Launching and Learners' Assessment, Teachers' Training in Mentoring Teachers on IMs Development, Online Workshop on Instructional Material Development for Beginning Readers with Focus on Design and Development, Online Workshop in Pedagogical Techniques on Beginning Reading for Home Teachers, and Webinar on Polishing the Pupil Learning Support Materials for Beginning Readers. All of which were attended by the teachers of the target public elementary school and other extension partner schools, home teachers, pre-service teachers and CEd faculty as BRPT facilitators. The activities began in 2019 and is continuing in this year 2021.

- Reading Intervention Related-Activities

Aside from the series of training conducted, BRPT implementers also hold consultative meetings with the community, responded to speaking engagements in the community, and conducted online tutorials of identified frustration level learners and non-readers. These activities were done with the observance of proper health protocol set by the IATF as it is understood that the implementation of BRPT was caught amidst the COVID-19 pandemic.

\section{- Development and Validation of Beginning Reading Instructional Materials}

The pre-service teachers as facilitators of BRPT were able to craft instructional materials in Beginning Reading Mother Tongue. They were patterned after the Strategic Intervention Materials or SIMs. There were 30 PLSMs developed and validated in total. The PLSMs were distributed among the home teachers as learning support materials alongside with the modules. Their primary purpose is to increase the reading competence of the learners through the use of the grade-level appropriate activities that can be accomplished by the learners with little or no help from the adults or home teachers.

The series of training, reading intervention related-activities, and the development and validation of beginning reading instructional materials were conducted to realize the BRPT objectives that is to increase the level of reading skills of the beginning readers.

Anent the results above, Torgersen (2011) has identified important characteristics of effective interventions for learners who have reading difficulties. These include: (1) interventions should be offered as soon as some evidence of student lagging behind the development of skills or knowledge critical to reading growth are found; (2) interventions must be guided by, and responsive to, data on student progress; and (3) interventions must be motivating, engaging, and supportive - a positive atmosphere is vital.

\section{Level of Reading Performance of the Primary Level Pupils After the BRPT Implementation}




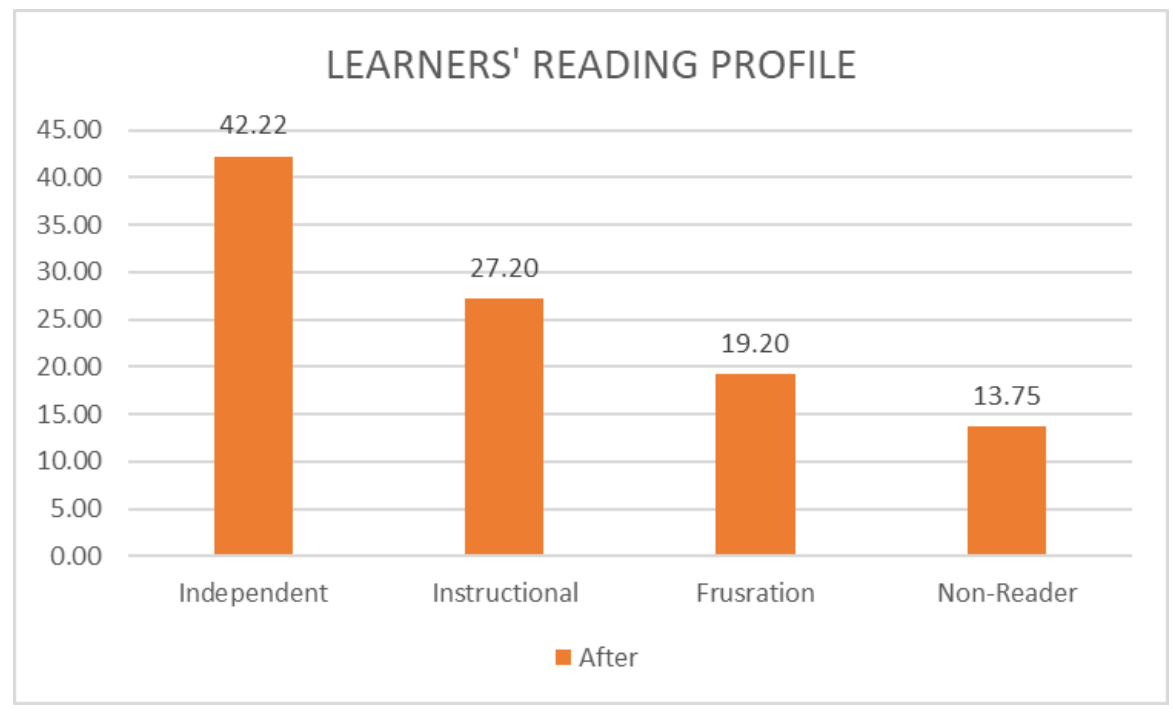

Fig. 3 The Learners' Reading Level After the BRPT Implementation

As gleaned in the figure above, out of 125 learners, $42.22 \%$ or 57 of them are in the independent level; 19.20 or 24 are in frustration level, and $13.75 \%$ or 11 of them are still non- readers. This means that majority of the learners can read independently with ease and without the assistance of an adult or teacher. The eleven (11) non-readers need much intervention for these pupils cannot blend sounds yet thus, they need an intensive reading intervention which can be done through online reading tutorial, one of the suggested activities in BRPT.

Comparison Between the Level of Reading Performance of the Primary Pupils Before and After the BRPT Implementation

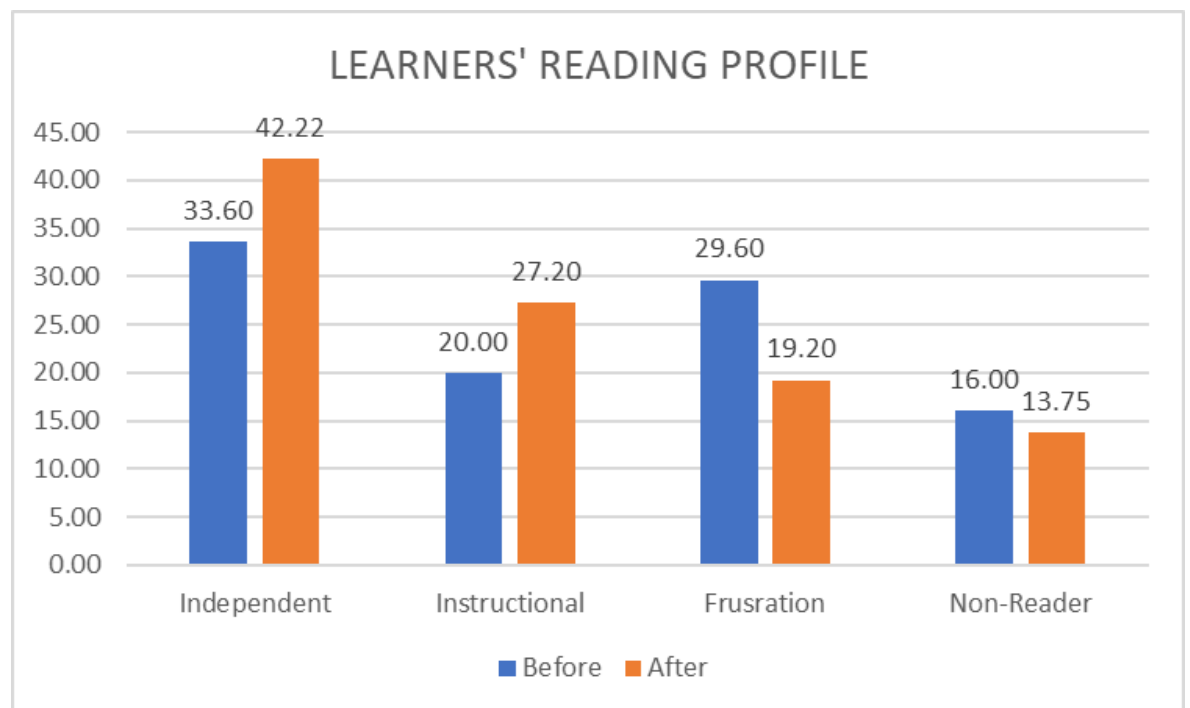

Fig. 4 The Learners' Reading Level Before and After the BRPT Implementation

As browsed in the figure above, a difference of $8.22 \%$ or 10 pupils were able to reach the independent level; $7.2 \%$ or 9 were able to reach the instructional level; $-10.4 \%$ or 13 learners were promoted to a much higher reading level; and $-2.25 \%$ or 3 among the learners were displaced or were able to reach to a higher level.

The remaining eleven (11) non-readers need much intervention thus, they need an intensive reading intervention which can be done through online reading tutorial, one of the suggested activities in BRPT.

In view of the results above, NDCP (2021) elucidated that parents should remain involved in their child's education. Families and community are responsible in the children's early literacy. Reading intervention programs can benefit all children, especially those that belong to underprivileged communities, by preventing the decrease of reading skills and promoting the fun in reading (Alexander \& Entwisle 1996 in NDCP, 2021). 


\section{Significant Difference Between the Level of Reading Performance of the Primary Pupils Before and After the BRPT Implementation}

As reflected in the table below, it can be noted that the p-value for both the instructional and non-readers are below the p-value set for analysis. Thus, indicating a significant difference between the reading levels of the learners before and after the BRPT implementation. Thus, the null hypothesis is rejected.

These findings reveal that the pupils in the aforesaid levels were able to improve their reading skills after the implementation of the BRPT. Thus, it can be said that the reading intervention program has improved the level of reading skills of the beginning readers and it was able to achieve its objective that is to improve the reading performance of the learners. 
Table 1

Significant difference on the reading levels of the learners before and after the BRPT implementation

\begin{tabular}{|c|c|c|c|}
\hline Variables & P-value & Remarks & Decision \\
\hline $\begin{array}{c}\text { Independent } \\
\text { Before } \\
\text { After }\end{array}$ & 0.064 & Not Significant & Fail to Reject \\
\hline $\begin{array}{c}\text { Instructional } \\
\text { Before } \\
\text { After }\end{array}$ & 0.031 & Significant & Reject Ho \\
\hline $\begin{array}{c}\text { Frustration } \\
\text { Before } \\
\text { After }\end{array}$ & 0.077 & Not Significant & Fail to Reject \\
\hline $\begin{array}{c}\text { Non-Reader } \\
\text { Before } \\
\text { After }\end{array}$ & 0.031 & Significant & Reject Ho \\
\hline
\end{tabular}

Significant at 0.05 level (2-tailed)

In connection to the result above, Foorman and Torgesen (2002) as cited in Cubillas and Ventura (2019) discovered in an evidencebased research that there is a dramatic reduction in the incidence of reading failure when explicit instruction in phonemic awareness and phonemic decoding skills, fluency in word recognition and text processing, construction of meaning, vocabulary, spelling, and writing components are provided by the classroom teacher. to deal with the needs of the learners most at risk of reading failure, the instructional components are relevant but they have to be made more explicit and comprehensive, more intensive, and more supportive reading intervention activities. The argument is formed that by coordinating research evidence from effective reading instruction with effective interventions, one can meet the literacy needs of all children.

Also, Young, Lagrone, and McCauley (2020) found similar positive results in their reading intervention program, Accordingly, a wellimplemented reading intervention combined with regular schooling improved the reading expression, reading rate and also the learners' decoding skills, word knowledge, and reading comprehension.

\section{Challenges Met by the Implementers of the BRPT}

The implementation of the BRPT as a reading intervention program is strengthened when the DepEd's Sulong Edukalidad: Battlecry Moving Forward Amidst the Pandemic was implemented. From then on, many problems have surfaced and such issues were gathered by the BRPT implementers via interview.

The results were consolidated and summarized into three (3) issues. They were the sudden shift of the training modality from face to face to virtual, home teachers' lack of participation to the training, and busyness brought about by overlapping of work schedules of the implementers of BRPT.

For the sudden shift of the training modality from face to face to virtual, implementers were shocked when classes were shut down due to the prevalence of COVID-19 and the declaration of the pandemic. This was supported by the statement of Participant 8 who said:

\footnotetext{
"We have not followed the suggested activities in our proposal since most of them are to be done in face-to-face set-up. In fact, there came a time, when we want to suspend the implementation of the project since we, at that time lacked options on how to carry on with the project".
}

Another challenge encountered in implementing the BRPT was the home teachers' lack of participation to the training. Because parents need to work and earn a living, they could hardly attend the training. Their lack of knowledge in maneuvering technology also presents a hindrance to their attendance to training. Such is evident in a statement made by a teacher-participant.

One participant commented:

$$
\begin{aligned}
& \text { "At first, parents were not able to attend the training since they were working and some of them are } \\
& \text { not familiar with technology. It's a good thing that we were able to help them by giving them assistance } \\
& \text { in using Google Meet and Zoom". }
\end{aligned}
$$

The busyness of the implementers of BRPT also became a challenge in the BRPT implementation. Some of them complained that Work-From-Home system made them busier because people have that notion that since they are at home, they are always free. The demand of their time has increased. Participant 5 stated:

"It would be better if the heads of the offices would consider that the employees who are in WFH mode 
are not always available. They too must see to it that as much as possible, the schedules of their meetings or training do not overlap with other university events or college event in the least."

Based on the statements above, the sudden shift of the training modality from face to face to virtual, home teachers' lack of participation to the training, and busyness brought about by overlapping of work schedules of the implementers of BRPT have direct impact on the implementation of the BRPT. They have to be addressed at once to ensure smooth-sailing conduct of the reading intervention program especially so that the program is still ongoing.

In reference to the statements above, Torgesen (2019) discerned that when a reading intervention starts, the simplest predictor of future reading growth is current reading achievement, and the most crucial indicators of the progress in learning to read during the initial elementary years are measures of word reading skill. To get hold of the information required, an assessment should be conducted. Such reading assessment must be complementary to the kind of assessment described for monitoring growth in word level reading skills.

\section{CONCLUSIONS}

Before the implementation of the reading intervention program, Beginning Reading Para sa mga Tsikiting, there were identified non-readers who needed much intervention for these pupils cannot blend sounds yet. Because of this, reading intervention activities were employed by BRPT to mitigate the number of non-readers and to enhance the reading performance of the primary grade pupils in general. Conduct of series of training, holding of reading intervention related-activities, and development and validation of beginning reading instructional materials were among the BRPT activities which all aimed to achieve the target objective of the reading intervention program. As a result, there is a significant improvement on the reading levels of the learners. However, there are still remaining few who need much assistance thus, they need an intensive reading intervention which can be done through online reading tutorial, one of the suggested activities in BRPT. Despite this result, it can still be said that the reading intervention program has improved the level of reading performance of the beginning readers and it was able to achieve its target objective. It must also be noted that this study cannot generalize outcomes of different reading intervention programs but the results of which however, may serve as basis for viable options for teachers, interventionists, reading program implementers working with learners who find reading difficult. During the course of the implementation of the BRPT, many problems had surfaced and such issues include the sudden shift of the training modality from face to face to virtual, home teachers' lack of participation to the training, and busyness brought about by overlapping of work schedules of the implementers of BRPT. The aforesaid issues have to be addressed at once to ensure smooth-sailing conduct of the reading intervention program especially so that the implementation of the extension program is still ongoing.

\section{ACKNOWLEDGMENT}

The authors would like to express their appreciation for the support of the collaborators of the extension project particularly the Elementary Education Department Faculty namely: Dr. Trixie E. Cubillas, Dr. Joyce M. Suganob, Dr. Marichu D. Tulang, Prof. Lourdes B. Bago, Mr. Leo L. Codilla, Jr., and Prof. Lita A. Bolivia, Dr. Gladys L. Lagura (the AGAK Center Director), the pre-service teachers, and the extension partner schools Pianing ES, Pedro Duncano ES, and especially the Babag ES teachers.

\section{REFERENCES}

Child Trends DataBank. (2019). Reading proficiency. https://www.childtrends.org/?indicators= reading-proficiency

Cubillas, T \& Ventura, R. 2019. Effectiveness of Small Group Instruction in Improving the Reading Skills of Grade Six Pupils: Basis for a Reading Intervention Program. International Journal of Scientific and Research Publications (IJSRP) 9(7):p91116 DOI: 10.29322/IJSRP.9.07.2019. p91116

National Center for Reading First Technical Assistance. 2005. A Principal's Guide to Intensive Reading Interventions for Struggling Readers in Reading First Schools. https://www2.ed.gov/programs/readingfirst/support/principal.pdf

National Economic Development Authority. 2016. AmBisyon Natin 2040. https://2040.neda.gov. ph/

NDCP, 2021.Early Literacy Development. https://dropoutprevention.org/effective-strategies/early- literacy-development/

Thums, K., Artelt, C. \& Wolter, I. 2020. Reading for entertainment or information reception? Gender differences in reading preferences and their impact on text-type-specific reading competences in adult readers. Eur J Psychol Educ 36, 339-357 (2021). https://doi.org/10. 1007/s10212-020-00486-1 
Torgesen, J. 2019. Reading Success: Skills, Interventions and Resources. https://www.reading horizons.com/reading-method/readingresearch/reading-success-skills-interventions-and- resources-2

Young, C. Lagrone, S. \& McCauley, J. 2020. Read Like Me: An Intervention for Struggling Readers. Education Sciences. file://C:/Users/CEd_IGF2020_NL2/Downloads/education-10-00057.pdf 